\title{
CORRELATION BETWEEN PLASMA TAMOXIFEN CONCENTRATION AND TUMOR RESPONSE IN PATIENTS WITH BREAST CANCER: AT NEOADJUVANT TREATMENT WITH TAMOXIFEN
}

\author{
BRUNO JOSE DUMET FERNANDES ${ }^{*}$, ANGELO DO CARMO SILVA MATTHES ${ }^{2}$, SERGIO BIGHETTI ${ }^{2}$, JULIANA \\ DUMET FERNANDES ${ }^{3}$, VERA LUCIA LANCHOTE ${ }^{4}$, CATHARINA RODRIGUES PINTO LOPES ${ }^{3}$
}

${ }^{1}$ Department of Clinical Analysis and Toxicology, Faculty of Pharmacy, Federal University of Bahia, Salvador, BA, Brazil, ${ }^{2}$ Department of Obstetrics and Gynecologic of Clinical Hospital of Faculty of Medicine of Ribeirão Preto, University of São Paulo, SP, Brazil, ${ }^{3}$ Department of Dermatology, Clinical Hospital Prof. Edgard Santos, Federal University of Bahia, Salvador, BA, Brazil, ${ }^{4}$ Department of Toxicology, Faculty of Pharmaceutical Sciences of Ribeirão Preto, University of São Paulo, Ribeirão Preto, SP, Brazil Email: bruno.dumet@ufba.br

Received: 28 Apr 2017 Revised and Accepted: 13 Jul 2017

ABSTRACT

Objective: to determine a possible correlation between the tumor response in patients suffering from breast cancer, initially treated with tamoxifen, and plasma concentration of this drug.

Methods: we studied 27 elderly patients (age range: 62 to 82 y) with advanced breast carcinoma who were treated with a daily dose of 20 mg of oral tamoxifen, for $3 \mathrm{mo}$. Responders were followed-up for $19 \mathrm{mo}$, and nonresponders for $21 \mathrm{mo}$. We measured plasma tamoxifen citrate levels in order to determine their possible correlation with objective remission of the disease.

Results: the correlation was found to be significant among responders (37\%), whose median plasma tamoxifen level was $187.40 \mathrm{ng} / \mathrm{ml}$, when comparing to non-responders, whose median plasma tamoxifen level was $99.52 \mathrm{ng} / \mathrm{ml}$. The frequency distribution of patients in both groups with concentration of tamoxifen lower and higher than $182.60 \mathrm{ng} / \mathrm{ml}$ was significant (fisher's test p-value $<0,0011$ ).

Conclusion: considering the results herein, we suggest that patients whose plasma tamoxifen levels reach $182.60 \mathrm{ng} / \mathrm{ml}$ after $3 \mathrm{mo}$ of treatment, with no tumor response, may not benefit from this treatment, and an alternative therapy should be regarded.

Keywords: Breast cancer, Tumor response, Plasma tamoxifen, Neoadjuvant

(C) 2017 The Authors. Published by Innovare Academic Sciences Pvt Ltd. This is an open access article under the CC BY license (http://creativecommons.org/licenses/by/4.0/) DOI: http://dx.doi.org/10.22159/ijpps.2017v9i9.19460

\section{INTRODUCTION}

Hormonal manipulation was one of the first modalities of palliative treatment among the therapies for breast cancer. Beatson [1] was the pioneer in this procedure, and reported tumor regression after bilateral oophorectomy in a young woman, suggesting that endogenous estrogen suppression could be effective for the treatment of breast cancer. It has been demonstrated that estrogens act on a variety of target cells in different tissues, inducing growth and/or expression of nuclear proteins.

One of the major additive treatments is based on the use of tamoxifen, which belongs to a group of compounds structurally different from estrogens because of their ability to interact with estrogen receptors, acting either as estrogen agonists or antagonists depending on the target tissue and the hormonal medium. Its specific effects on tissues differ from those of estradiol, properties that characterise it as a selective estrogen receptor modulator [2].

There is no doubt that its role as a blocker of estrogen-binding to its receptor by its own binding to the receptor promotes an antagonistic antiestrogen effect. Another mechanism of its antiproliferative action is the induction of growth factors (TGF- $\beta$ ), which acts as a negative intracellular regulator by an autocrine action when produced intracellularly, or by a paracrine action when produced by mammary tissue stroma [3].

Tamoxifen is indicated for the primary endocrine treatment of advanced breast cancer, as well as an alternative for patients who did not respond to other hormonal therapies. Administered orally, it is rapidly absorbed, reaching a maximal plasma concentration within $4-7 \mathrm{~h}$ and reaching a steady state corresponding to 3 to 5 times its half-life after 4 to $6 \mathrm{w}$. It then remains at constant levels, and is metabolised by hydroxylation and conjugation, and slowly excreted through the kidneys and intestine [4]. The recommended dose is 20 to $40 \mathrm{mg}$. day ${ }^{-1}$ divided into two doses, and a higher dose of $200 \mathrm{mg}$. day ${ }^{-1}$ does not seem to improve the results [5]. When the drug is administered orally and continuously for 10 or $12 \mathrm{mo}$, an effective response is obtained in about $30 \%$ of cases. An increase in response to $60 \%$ is observed in the presence of estrogen receptor concentrations of $100 \mathrm{fmol}$. $\mathrm{pg}^{-1}$ protein or more [6]. The best responses have been observed in women with at least $5 \mathrm{y}$ of menopause, although a response is also observed before menopause. However, in postmenopausal women with operable breast cancer, with positive axillary lymph nodes and positive estrogen receptors (ER), tamoxifen at the dose of $20 \mathrm{mg}$. day ${ }^{-1}$ by the oral route should be considered as the adjuvant therapy of choice [5]. Tamoxifen being the first SERM characterized as an anti-estrogen in the treatment of breast cancer. Subsequent to its development for the same, it was observed that tamoxifen exhibited estrogen agonist effect on the skeleton and the liver [7].

In the adjuvant setting it has been shown that $5 \mathrm{y}$ of tamoxifen treatment reduces the rate of disease recurrence by almost forty percent and breast cancer mortality by thirty percent during the first $15 \mathrm{y}$. Extended tamoxifen therapy, for up to $10 \mathrm{y}$, appeared to be superior to $5 \mathrm{y}$, with further reductions of $25 \%$ and $29 \%$ in the risk of recurrence and mortality. Tumor shrinkage and prolonged survival have been observed in the metastatic disease. Nevertheless, disease recurs in approximately $30 \%$ and non-response is also observed in about $50 \%$ of the patients with metastatic disease $[8,9]$.

An objective full or partial response depends on receptor concentration, and it is best when ER and progestogen receptors (PgR) are observed. Less than a 5\% response has been obtained for ER-(negative), a 10 to $15 \%$ response has been obtained for ER lower than $10 \mathrm{fmol}$, a 30 to $45 \%$ response for $\mathrm{ER+(positive)} \mathrm{of} 10$ to $25 \mathrm{fmol}$, and a 60 to $80 \%$ response for ER+higher than $25 \mathrm{fmol}$ [10]. Different responses to tamoxifen treatment have been reported 
according to the dose used. Westerberg et al. [11] reported that $1 / 3$ of their patients who did not respond to the $40 \mathrm{mg}$ dose responded to $80 \mathrm{mg}$ a day. Mouridsen et al. [12] reported that a patient who did not respond to a daily dose of $30 \mathrm{mg}$ tamoxifen responded when the dose was increased to $90 \mathrm{mg}$ a day, results confirmed by Manni et al. [13] with a patient whose daily dose was increased from 20 to $40 \mathrm{mg}$. Till date, it is not known whether plasma tamoxifen concentrations interfere with the interaction of these factors and thus with the response to treatment. Considering that the mechanism of action of tamoxifen has not yet been fully established and in view of the wide use of this medication as a hormonal treatment of breast cancer, we undertook the present study in and attempt to clarify the real role of this medication in hormonal therapy in order to determine a clear advantage for patients who would indeed benefit from the use of the drug. We also wanted to determine a possible correlation between the tumor response of patients with breast cancer initially treated with tamoxifen and the plasma concentration of the ingested medication.

\section{MATERIALS AND METHODS}

\section{Patients}

The study was approved by the Ethics Committee of the University Hospital, Faculty of Medicine of Ribeirão Preto, University of São Paulo-Process $n \circ 2719 / 2005$. Patients seen in the Sector of Gynecologic and Mammary Oncology of the Department of Gynecology and Obstetrics of the University Hospital, Faculty of Medicine of Ribeirão Preto, with a diagnosis of breast cancer were prospectively followed up after clinical staging. We selected patients with stage IIb and III tumours and with at least $5 \mathrm{y}$ of post menopause, with duration of the complaints of more than 4 mo and with no signs of inflammation or transition phenomena. All patients were submitted to initial clinical evaluation when staging, tumor measurement and the data were recorded according to a preestablished protocol, and 8 of them as control, a collection of $10 \mathrm{ml}$ blood were performed.

All patients were submitted to an incisional biopsy of the tumor for histological study of tumor type, mitotic index, tubular formation and nuclear atypia, as well as for histochemical study for the determination of hormonal receptors as described by Hsu et al. [14]. After histological confirmation, all patients received tamoxifen citrate at the dose of $20 \mathrm{mg}$. day ${ }^{-1}$, ingested at night. All patients were followed up monthly for three months for evaluation of tumor response on the basis of tumor size measurement.

After this time, $10 \mathrm{ml}$ blood was collected into a heparinized flask and centrifuged at $10,000 \mathrm{rpm}$ for $10 \mathrm{~min}$. Plasma was then aspirated and stored in a glass tube at $-20^{\circ} \mathrm{C}$ until the time for reading. This sample was used for the study of tamoxifen concentrations by chromatography.

\section{Analysis of tumor response}

On the occasion of the first staging visit, the patient was submitted to measurements of the two widest diameters of the tumor with a Mitutoyo pachymeter by at least two examiners. These tumor measurements were repeated monthly in the same manner. After three months, a full response was considered to have occurred when the lesion disappeared, a partial response was considered to be present when the tumor volume decreased by $50 \%$ or more of its initial volume, and progressive disease was considered to have occurred when the initial volume increased or when new lesions appeared, according to the criteria recommended by the 1979 WHO Handbook for Reporting Results of Cancer Treatment [15].

\section{Analysis of tamoxifen in plasma}

\section{Standard solutions and reagents}

A stock solution of tamoxifen citrate $(100 \%$, Research Biochemical International, Natick, MA, USA) was prepared at the concentration of $500 \mu \mathrm{g}$. $\mathrm{ml}^{-1}$ methanol, and used to prepare solutions diluted in methanol at concentrations of $20,10,4,2$, and $1 \mu \mathrm{g}$. $\mathrm{ml}^{-1}$. The nitrazepam solution used as an internal standard was prepared in methanol at the concentration of $100 \mu \mathrm{g}$. $\mathrm{ml}^{-1}$. The solvents used for sample preparation were residue grade (Merck, Darmstadt, Germany).

\section{Sample preparation}

Plasma aliquots $(1,000 \mu \mathrm{L})$ with $25 \mu \mathrm{L}$ of the nitrazepam solution added were extracted with $5 \mathrm{ml}$ hexane-isoamylic acid (98.5:1.5, $\mathrm{v} / \mathrm{v}$ ) for $30 \mathrm{~min}$ in a horizontal shaker at $220 \pm 10$ cycles. $\mathrm{min}^{-1}$. After centrifugation at $1800 \mathrm{~g}$ for $5 \mathrm{~min}$, the organic phases were transferred to conical tubes and evaporated dry under an air flow at room temperature. The residues were reconstituted with $25 \mu \mathrm{L}$ acetone and submitted to chromatography.

\section{Calibration curve}

The calibration curve was obtained after enrichment of $1000 \mu \mathrm{L}$ blank plasma (obtained from volunteers who had not been treated with any medication for the last $72 \mathrm{~h}$ ) with $25 \mu \mathrm{L}$ of each standard tamoxifen solution $(25-500 \mathrm{ng} / \mathrm{ml}$ in plasma). The enriched samples were submitted to the extraction procedure described above.

\section{Chromatographic analysis}

A Shimadzu GC-17A gas chromatography apparatus equipped with a thermoionic FTD-17 flame detector and a C-R6A integrator was used. Tamoxifen and the internal standard were separated on a 0.25 $\mathrm{mm} \times 30 \mathrm{~m}$ fused silica SPB $®$ capillary column (Supelco, Bellefonte, PA, USA) with a $0.25 \mu \mathrm{m}$-thick film.

The chromatography apparatus was operated with the injector at 270 ${ }^{\circ} \mathrm{C}$, the detector at $280^{\circ} \mathrm{C}$, and with an oven temperature programmed for $60^{\circ} \mathrm{C}$ for $1 \mathrm{~min}$, and with an increase of $100^{\circ} \mathrm{C}$. $\mathrm{min}^{-1}$ up to $270{ }^{\circ} \mathrm{C}$, with a $15 \mathrm{~min}$ permanence at the highest temperature. Were injected $2 \mu \mathrm{l}$ in the splitless mode. Helium was used as the mobile phase at $120 \mathrm{kPa}$.

\section{Histological analysis of tumor tissue}

The biopsy material was dehydrated in a growing alcohol series, cleared in xylene and embedded in paraffin; 5-6 $\mu \mathrm{m}$ thick slides were obtained with a microtome, and later deparaffinized, re-hydrated, and mounted on slides for reading.

\section{RESULTS}

From February 1995 to August 1998 we followed up 27 patients ranging ageing from 62 to $82 \mathrm{y}$ (median: $71 \mathrm{y}$; mean: $71.33 \mathrm{y}$ ). A total of 35 blood samples were obtained from the 27 patients; 8 of them obtained as a control before treatment, and the remaining 27 after 3 mo of treatment. No tamoxifen was detected in the plasma from 8 controls before (table 1).

Table 1: Distribution of control patients with respect to tamoxifen concentration

\begin{tabular}{llll}
\hline Patient number & Age $\mathbf{( y )}$ & Tamoxifen $(\mathbf{n g} / \mathbf{m l})$ & Response \\
\hline 6 & 66 & Not detected & Control \\
9 & 68 & Not detected & Control \\
11 & 66 & Not detected & Control \\
12 & 75 & Not detected & Control \\
13 & 73 & Not detected & Control \\
15 & 78 & Not detected & Control \\
17 & 64 & Not detected & Control \\
19 & 65 & Not detected & \\
\hline
\end{tabular}




\section{Tumor response}

Table 2 shows the distribution of patients treated with tamoxifen citrate according to tumor volume clinically determined before and after treatment, and according to the anatomopathological findings regarding the tumor response in the surgical piece. Table 3 shows the distribution of patients with advanced breast cancer according to the response obtained, defined on the basis of the $1979 \mathrm{WHO}$ Classification [15]. The distribution is also presented graphically in fig. 1.

Analysis of the tumor response permitted us to divide the patients into two groups, i.e., those who responded to treatment (group R), and those who did not (group N).

Table 2: Distribution of the patients treated with tamoxifen citrate according to tumor volume clinically determined before and after treatment and according to the anatomopathological findings regarding the tumor response in the surgical piece

\begin{tabular}{|c|c|c|c|c|c|c|}
\hline Case & Size before treatment & Initial volume & Size after treatment & Volume after treatment & Surgical piece & Response \\
\hline 1 & $10.0 \times 10.0$ & 100 & $4.0 \times 3.0$ & 12 & $4.0 \times 2.5$ & Partial \\
\hline 2 & $5.6 \times 4.8$ & 26.88 & $4.8 \times 4.6$ & 22.08 & $5.0 \times 1.5$ & None \\
\hline 3 & $3.5 \times 4.0$ & 14 & $4.5 \times 4.3$ & 19.35 & $4.4 \times 4.0$ & Disease progress \\
\hline 4 & $5.8 \times 3.2$ & 18.66 & $4.2 \times 3.6$ & 15.12 & not operated & None \\
\hline 5 & $4.5 \times 4.0$ & 18 & $3.0 \times 3.5$ & 10.5 & $4.5 \times 4.0$ & None \\
\hline 6 & $4.5 \times 3.5$ & 15.75 & $2.2 \times 1.8$ & 3.96 & no medication & Partial \\
\hline 7 & $5.2 \times 4.1$ & 21.32 & $5.0 \times 5.1$ & 25.5 & $2.5 \times 1.5$ & Disease progress \\
\hline 8 & $5.3 \times 7.0$ & 37 & $0.0 \times 0.0$ & 0 & absente & Full \\
\hline 9 & $4.4 \times 3.2$ & 14.06 & $4.0 \times 3.8$ & 15.2 & $4.5 \times 3.5$ & Disease progress \\
\hline 10 & $2.1 \times 1.8$ & 3.78 & $2.5 \times 2.1$ & 5.25 & $5.0 \times 2.0$ & Disease progress \\
\hline 11 & $2.4 \times 2.8$ & 6.72 & $2.0 \times 2.0$ & 4 & $1.5 \times 1.5$ & None \\
\hline 12 & $8.5 \times 6.1$ & 51.85 & $9.0 \times 5.0$ & 45 & $7.5 \times 7.2$ & None \\
\hline 13 & $7.0 \times 5.0$ & 35 & $2.0 \times 2.0$ & 4 & no medication & Partial \\
\hline 14 & $7.0 \times 4.0$ & 28 & $5.5 \times 30$ & 16.5 & $3.0 \times 2.0$ & None \\
\hline 15 & $5.0 \times 5.2$ & 26 & $0.0 \times 0.0$ & 0 & $3.0 \times 2.5$ & $\mathrm{RC}$ \\
\hline 16 & $5.3 \times 3.6$ & 19.08 & $5.0 \times 4.0$ & 20 & $3.0 \times 3.0$ & Disease progress \\
\hline 17 & $5.2 \times 4.7$ & 24.44 & $5.2 \times 4.3$ & 22.36 & no medication & None \\
\hline 18 & $6.6 \times 5.8$ & 38.28 & $6.0 \times 4.5$ & 27 & $5.0 \times 5.0$ & None \\
\hline 19 & $4.5 \times 3.2$ & 14.4 & $4.5 \times 3.2$ & 14.4 & not operated & None \\
\hline 20 & $5.0 \times 5.0$ & 25 & $4.7 \times 4.8$ & 22.56 & not operated & None \\
\hline 21 & $5.8 \times 5.2$ & 30.16 & $5.1 \times 5.6$ & 28.56 & $6.0 \times 5.0$ & None \\
\hline 22 & $4.8 \times 5.0$ & 19.2 & $4.2 \times 4.2$ & 17.64 & $3.0 \times 2.5$ & None \\
\hline 23 & $3.0 \times 3.0$ & 9 & $0.0 \times 0.0$ & 0 & absente & Full \\
\hline 24 & $2.4 \times 1.8$ & 4.32 & $0.0 \times 0.0$ & 0 & residual & Full \\
\hline 25 & $4.9 \times 3.9$ & 19.17 & $0.0 \times 0.0$ & 0 & not operated & Full \\
\hline 26 & $5.6 \times 3.3$ & 17.92 & $0.0 \times 0.0$ & 0 & absente & Full \\
\hline 27 & $5.6 \times 4.4$ & 26.64 & $2.0 \times 2.0$ & 4 & $2.5 \times 2.0$ & Partial \\
\hline
\end{tabular}

Table 3: Distribution of patients with advanced breast cancer according to the response obtained, defined on the basis of the 1979 WHO classification

\begin{tabular}{|c|c|c|c|}
\hline Tumor response & $\mathrm{N}^{\circ}$ of patients and $\%$ & Response & Frequency \\
\hline Full & $6(22.2 \%)$ & Present & $10(37 \%)$ \\
\hline Partial & $4(14.8 \%)$ & - & - \\
\hline None & $12(44.4 \%)$ & None & $17(63 \%)$ \\
\hline Progressive disease & $5(18.5 \%)$ & - & - \\
\hline Total & $27(100 \%)$ & - & $27(100 \%)$ \\
\hline
\end{tabular}

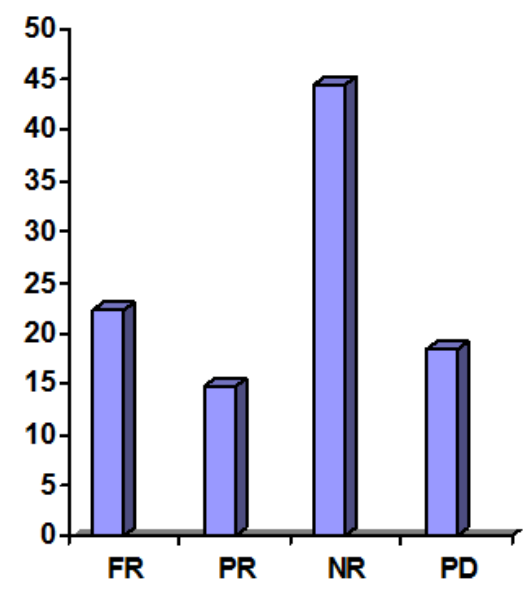

Fig. 1: Distribution of patients with advanced breast cancer according to the response obtained (FR-full response; PR-partial response; NR-no response; PD-progressive disease) 
Correlation between tumor response and plasma tamoxifen levels

The tamoxifen levels detected in the plasma of patients who responded to treatment are listed in table 4 , and those of the patients who did not respond are listed in table 5. Mean age of responders was $71.8 \mathrm{y}$ (range: 66 to $80 \mathrm{y}$ ), and the mean age of non- responders group was 70.88 y (range: 62 to 82 y). The two groups did not differ significantly $(P$-value $=0.74)$ in age.

The correlation was found to be significant among responders (37\%), whose median plasma tamoxifen level was $187.40 \mathrm{ng} / \mathrm{ml}$, as compared to non-responders (63\%), whose median plasma tamoxifen level was $99.52 \mathrm{ng} / \mathrm{ml}$.

Table 4: Distribution of patients with advanced breast carcinoma who responded to treatment with tamoxifen citrate according to plasma tamoxifen concentration, age and observed tumor response

\begin{tabular}{llll}
\hline Patient number & Patient age (years) & Plasma tamoxifen $(\mathbf{n g} / \mathbf{m l})$ & Observed response WHO, 1979) \\
\hline 1 & 71 & Not detected & Partial \\
6 & 66 & 44.91 & Partial \\
8 & 80 & 54.52 & Full \\
13 & 73 & 101.32 & Partial \\
15 & 78 & 108.04 & Full \\
23 & 66 & 192.58 & Full \\
24 & 67 & 206.38 & Full \\
25 & 74 & 210.25 & Full \\
26 & 72 & 240.66 & Full \\
27 & 71 & 527.97 & Partial \\
\hline
\end{tabular}

Mean plasma tamoxifen concentration for the group of response: 187.4ng.mL-1

Table 5: Distribution of patients with advanced breast carcinoma who did not respond to treatment with tamoxifen citrate according to plasma tamoxifen concentration, age and observed tumor response

\begin{tabular}{llll}
\hline Patient number & Patient age (years) & Tamoxifen (ng/ml) & Observed response (WHO, 1979) \\
\hline 2 & 74 & Not detected & None \\
3 & 70 & Insufficient material & Disease progress \\
4 & 82 & 34.11 & None \\
5 & 74 & 40.1 & None \\
7 & 72 & 52.39 & Disease progress \\
9 & 68 & 54.64 & Disease progress \\
10 & 70 & 66.81 & Disease progress \\
11 & 66 & 75.97 & None \\
12 & 75 & 80.82 & None \\
14 & 74 & 102.12 & None \\
16 & 67 & 109.63 & Disease progress \\
17 & 64 & 120.06 & None \\
18 & 76 & 122.99 & None \\
19 & 65 & 143.02 & None \\
20 & 68 & 150.46 & None \\
21 & 62 & 157,16 & None \\
22 & 78 & 182,60 & None \\
\hline
\end{tabular}

Mean plasma tamoxifen concentration for the group of non-responders: $99.52 \mathrm{ng} \cdot \mathrm{mL}-1$

Taking 182.60ng/ml as the reference value for tamoxifen concentration, and the cut-off value established by the ROC curve, which represents the concentration for the two groups with the best accuracy, we determined the frequency distribution of plasma tamoxifen levels in relation to tumor response, as shown in table 6. It can be seen that the difference in the response rate between the two groups of tamoxifen concentration was significant by the Fisher's test.

Fig. 2 shows the frequency distribution and fig. 3 shows the cumulative frequency curve for tamoxifen concentration, which was significant by the unpaired T-test $(P$-value<0.0201), and by analysis of variance by the Fisher's test $(P$-value $<0.0011)$.

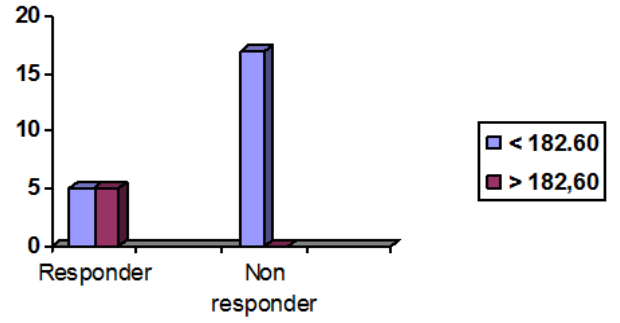

Fig. 2: Frequency distribution of plasma tamoxifen concentrations according to tumor response

Table 6: Frequency distribution of plasma tamoxifen concentrations according to tumor response

\begin{tabular}{lll}
\hline Plasma tamoxifen $(\mathbf{n g} / \mathbf{m l})$ & Responder group $\mathbf{N}$ & Non-responder group N \\
\hline$<182.60$ & 5 & 17 \\
$>182.60$ & 5 & 0 \\
Total & 10 & 17 \\
\hline
\end{tabular}

Fisher's test: $\mathrm{P}<0,0011$ Unpairedt test: $\mathrm{P}<0,0201$ 


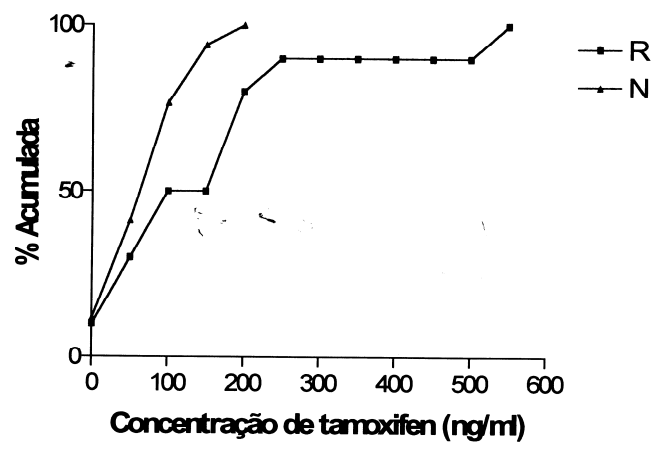

Fig. 3: Cumulative frequency curve for tamoxifen concentration, according tumor response

Correlation between tumor response and time of patient followup in the responder and non-responder groups
Patient survival according to tumor response was determined and is presented in table 7 , which shows the distribution of the two groups according to follow-up time. The proportions of surviving patients, the cumulative survival rate according to response group and the survival curve corrected for each group are illustrated in fig. 4 and 5, respectively.

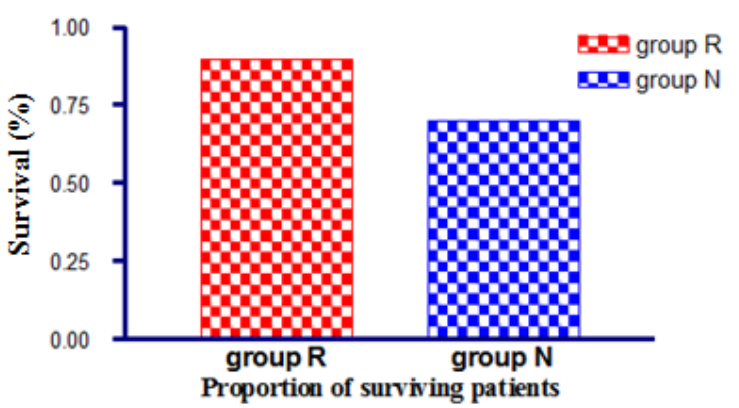

Fig. 4: Proportion of surviving patients according to tamoxifen treatment response for each group

Table 7: Distribution of the two groups of patients treated with tamoxifen according to response to treatment and survival

\begin{tabular}{|c|c|c|c|c|c|}
\hline \multicolumn{3}{|l|}{ Responders } & \multicolumn{3}{|c|}{ Non-responders } \\
\hline Patient $n^{\circ}$ & Response observed & Survival (mo) & Patient $^{\circ}{ }^{\circ}$ & Response observed & Survival (mo) \\
\hline 1 & Partial & 17 & 2 & None & 33 \\
\hline 6 & Partial & 20 & 3 & Disease progression & $22+$ \\
\hline \multirow[t]{4}{*}{8} & Full & 21 & 4 & None & 11 \\
\hline & & & 5 & None & 12 \\
\hline & & & 7 & Disease progression & $11+$ \\
\hline & & & 9 & Disease progression & 21 \\
\hline \multirow[t]{4}{*}{13} & Partial & 10 & 10 & Disease progression & $10+$ \\
\hline & & & 11 & None & 33 \\
\hline & & & 12 & None & $22+$ \\
\hline & & & 14 & None & 36 \\
\hline 15 & Full & $31+$ & 16 & Disease progression & $14+$ \\
\hline 23 & Full & 17 & 17 & None & 17 \\
\hline 24 & Full & 21 & 18 & None & $15+$ \\
\hline 25 & Full & 11 & 19 & None & $31+$ \\
\hline 26 & Full & 40 & 20 & None & 20 \\
\hline \multirow[t]{2}{*}{27} & Partial & 21 & 21 & None & 35 \\
\hline & & & 22 & None & 32 \\
\hline
\end{tabular}

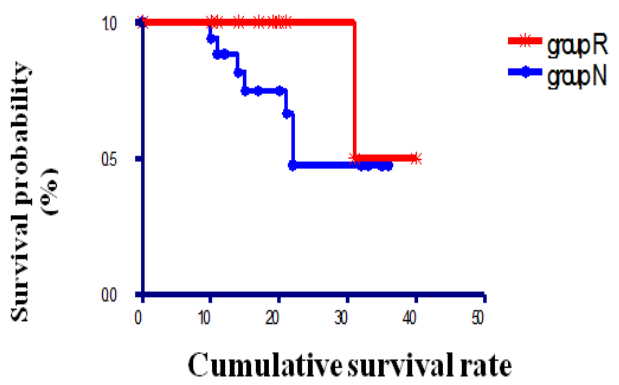

Fig. 5: Cumulative survival rate according to tamoxifen treated response group

\section{DISCUSSION}

Tamoxifen citrate is a selective modulator of estrogen receptors with antitumor properties and has been playing an increasingly important role in the treatment of patients with breast cancer in all of its stages over the last $20 \mathrm{y}$. More than 3,000,000 women have been treated with tamoxifen so far [16]. Tamoxifen can be used to treat polycystic ovarian syndrome (PCOS), the most common endocrine disorder in women [18]. On the order hand, tamoxifen can be a secondary case of nephrotic disorder [19]. A study of 40 randomized trials involving 30,000 women suffering from breast cancer undergoing treatment with tamoxifen demonstrated that during a 10 y follow-up period there was a $25 \%$ decrease in annual recurrence, a $17 \%$ decrease in mortality rate, and a $39 \%$ decrease in recurrence in the contralateral breast [17].

The correlation of the tumor response of the patients studied with tamoxifen levels was determined in only 24 cases. In one case, the plasma sample was insufficient because it was first used for liquid chromatography, an inadequate procedure that was replaced with gas chromatography. This patient presented progressive disease and, in her case, it was not possible to determine the correlation of the response with plasma tamoxifen concentration. As to the other two patients who reported the use of the medication on the preceding day and whose plasma did not show the presence of tamoxifen, a fact also reported by Peyrade et al. [20], the following explanations may be proposed: elderly patients may no longer want to take the medication but say that they take it to avoid embarrassment, the medication was falsified (a fact that may be occurring based on lay media reports), or the patients took the medication up to one month before blood collection, this being the time of tamoxifen permanence in blood [22], and did not respond to its pharmacological action.

The study of tumor response showed that 6 patients $(22.2 \%)$ had a full response, 3 of them presenting no tumor in the anatomopathological study, and $4(14.8 \%)$ presented a partial response, for a total of 10 patients $(37 \%)$ with a response. In contrast, 17 patients (63\%) did not respond, with 12 of them 
(44.4\%) showing no response, and 5 (18.5\%) showing progressive disease. These results are similar to those reported by Meriel et al. [23], who obtained a $42 \%$ response rate and a $58 \%$ rate of no response under identical treatment conditions, and also similar to those reported by others $[13,14,21,25-26]$.

Ward [26] detected a $20 \%$ response rate in patients who presented more than $50 \%$ regression of the initial tumor volume, or a $77 \%$ response rate when tumor stabilization or simply a tumor reduction was considered, with a posology of $20 \mathrm{mg}$ tamoxifen twice a day, and a lower response rate when the dose was $10 \mathrm{mg}$ twice a day. Andrade et al. [21] reported a 58.8\% rate of good responses with the use of $20 \mathrm{mg}$ daily. In a study of 300 patients who used tamoxifen as neoadjuvant treatment, Ward et al. [27] reported 1/3 of objective responses for patients with metastatic breast cancer. However, the results of this treatment are controversial because of the few clinical studies of this type reported in the literature $[20,26]$.

In the present study, no tamoxifen concentration was detected in one of the patients who had a partial response, indicating that this patient had taken the medication up to at least $6 \mathrm{w}$ before determination, the maximum time during which tamoxifen is detected after ingestion, with her response occurring during the first 2 mo. The plasma tamoxifen concentration in the responder group ranged from 44.91 to $527.97 \mathrm{ng} / \mathrm{ml}$, with a median of $187.40 \mathrm{ng} / \mathrm{ml}$ for 9 patients (excluding the patient with no detectable tamoxifen levels). This suggests that plasma tamoxifen concentration per se may not be a major factor for the induction of a tumor response since the patients with the lowest $(44.91 \mathrm{ng} / \mathrm{ml})$ and the highest $(527.97 \mathrm{ng} / \mathrm{ml})$ levels in the group had the same type of response (partial).

Also in the non-responder group, plasma tamoxifen concentration itself was not responsible for the absence of a response since the response was absent both in the patient with lowest plasma tamoxifen level $(34.11 \mathrm{ng} / \mathrm{ml})$ and in the patient with the highest level $(182.60 \mathrm{ng} / \mathrm{ml})$, and the mean for this group was $99.52 \mathrm{ng} / \mathrm{ml}$ for 15 (when the two patients with undetectable tamoxifen levels are excluded).

When the reference value of $182.60 \mathrm{ng} / \mathrm{ml}$ is considered and the frequency of levels above or below this value is considered, it can be seen that there was a significant difference in the response rate between the two groups of tamoxifen concentrations by the exact Fisher's test $(P$-value $<0.0011)$ and by the unpaired $t$ test, in agreement with the questions raised by Manni et al. [13] about better responses with higher doses. In the present study, of the 6 patients with the best response (full response), only 1 had a plasma tamoxifen concentration below 190ng/ml and the mean for the 6 patients was $238.72 \mathrm{ng} / \mathrm{ml}$, representing a strong indication of a dose-response relationship.

Tamoxifen has been used for $20 \mathrm{y}$ for the treatment of breast cancer and the recommended daily dose has been modified several times over this period of time. Mouridsen et al. [12], in a dose-response study, observed that 28\% (132 of 471) patients treated with $20 \mathrm{mg}$. day $^{-1}$ tamoxifen obtained objective remission compared to 170 of 432 patients treated with $40 \mathrm{mg}$. day ${ }^{-1}$ who obtained a $39 \%$ rate of objective responses, suggesting that higher doses can have a stronger antitumor effect. However, today the dose is well established about $20 \mathrm{mg}^{-}$day ${ }^{-1}$, since higher doses did not result in better responses [26], although the plasma level of this medication has not been previously correlated with response to treatment.

The plasma tamoxifen concentrations detected in the present study ranged from 34.11 to $527.97 \mathrm{ng} / \mathrm{ml}$. Adam [28] reported that, because of the long half-life of tamoxifen there is a cumulative effect of the daily drug ingestion, showing that a daily ingestion of $10 \mathrm{mg}$ presents an initial peak of $18 \mathrm{ng} / \mathrm{ml}$, with an increase to $125 \mathrm{ng} / \mathrm{ml}$ after $21 \mathrm{~d}$. After administering a daily tamoxifen dose of $20 \mathrm{mg}$, Wada et al. [29] detected stable tamoxifen levels after $8 \mathrm{w}$ of treatment $(273.3 \mathrm{ng} / \mathrm{ml})$, and Patterson [30] detected a significant peak of $285 \mathrm{ng} / \mathrm{ml}$ after $4 \mathrm{w}$ of ingestion of the same dose, which remained constant for an additional $28 \mathrm{w}$. When they measured the metabolite desmethyl tamoxifen, they detected a significant value of $477 \mathrm{ng} / \mathrm{ml}$ after $8 \mathrm{w}$, which remained constant thereafter. After tamoxifen biotransformation occurs, elimination is quite slow, with a half-life of $12 \mathrm{~d}$.

These data explain the wide variability of the values detected for plasma tamoxifen concentration since there are intrinsic factors of absorption, metabolic processing and excretion of the drug by different patients. Thus, the lower concentrations detected reveal that there may be faulty drug absorption, increased metabolism and excretion or that the medication does not contain the dose it should in each tablet. The detection of higher values is probably due to the cumulative effect of the drug in patients with good absorption and taking tablets that contain the real dose. Also, the fact that our patients are older may explain the variability in tamoxifen concentration among them due to alterations in enzymes of the cytochrome 450 family, which catalyze a series of reactions concerning drug metabolism, among them tamoxifen [31].

Age did not differ between groups, since the medication was used by women selected for age, with similar mean values of $71.80 \mathrm{y}$ for the responder group and 70.88 y for the non-responder group $(P$ value $=0.74$ ). Staging also showed no significant differences because the patients were selected for advanced cancer, with similar staging for both groups $(P$-value $=1)$. Five patients were in stage IIIb, 4 in stage IIIa and 1 in stage IIb in the responder group, and 8 patients were in stage IIIb, 7 in stage IIIa and 2 in stage IIb in the nonresponder group.

Evaluation of the survival curve showed 1 death in the group that responded to treatment during the study period $(10 \%)$, and 7 deaths in the group that did not respond (41\%), showing a greater survival for the responder group. Although overall survival tended to be longer for the responder group, with a mean of $35.5 \mathrm{mo}$, compared to 22 mo for the non-responder group, it did not differ significantly between groups $(P-$ value $=0.2523$ ) by the log rank test.

Finally, it is noteworthy that conversion of tamoxifen to its principal metabolite (endoxifen) by the enzyme CYP2D6 is required for achieving drug's anticancer effects [32, 33]. Genetic variants of CYP2D6 may affect response to tamoxifen, and lower concentrations of endoxifen have been associated with inferior breast cancer outcomes in numerous retrospective trials [33]. Nevertheless, there is still no agreement on the clinical utility of CYP2D6 genotype as biomarker for the prediction of breast cancer outcome [32]. Ruddy et al. [34] found that patients with low endoxifen $(<6 \mathrm{ng} / \mathrm{ml})$ plasma concentrations or poor metabolizers of tamoxifen should consider another treatment. On this view, a recent study found that the variability associated with tamoxifen metabolism may be eliminate by administering endoxifen by oral route, leading to a more predictable efficacy [34].

The use of endoxifen in breast cancer patients is now being tested in clinical trials. However, as tamoxifen and other metabolites may also contribute to the overall clinical effect of tamoxifen, the sole administration of endoxifen may not be the optimal strategy. Therefore, a dosing strategy of tamoxifen at a dose of $20 \mathrm{mg}$ in combination with endoxifen (at a dose dependent on CYP2D6 phenotype) has been suggested to be a better approach [35]. Nevertheless, these approaches need further investigation [32].

\section{CONCLUSION}

In conclusion, tamoxifen citrate as neoadjuvant treatment of advanced breast cancer induced a tumor response in $37 \%$ of the patients, with full remission in $22 \%$. Plasma tamoxifen levels were increased in patients who responded, with a significant difference $(P$-value $<0.0011)$ when the frequency distribution of levels below and above $182.60 \mathrm{ng} / \mathrm{ml}$ were compared. The group that did not respond to treatment showed a higher mortality rate and the cumulative survival rate did not differ between groups. Finally, if patients who regularly take tamoxifen citrate do not show plasma levels of the drug above $182.60 \mathrm{ng} / \mathrm{ml}$ after 3 mo of treatment and do not respond clinically, they will probably not benefit from taking this medication. However, studies with a larger number of patients are needed to support this statement. 


\section{ACKNOWLEDGEMENT}

To Mr. Natalino Bocardo and Mrs. Maria Paula for the technical laboratory support in the drug plasma measurements by HPLC.

\section{AUTHOR CONTRIBUTION}

All authors participated equally on the production of the manuscript and the work was carried on according to the ethical requirements of our institution

\section{CONFLICT OF INTERESTS}

The authors have no conflicts of interest that are directly relevant to the content of this study.

\section{REFERENCES}

1. Beatson GT. On the treatment of inoperable cases of carcinoma of the mamma. Suggestions for a new method of treatment with illustrative cases. Lancet 1986;2:104-7.

2. Sato M, Glasebrook AL, Bryant HU. Raloxifene: a selective estrogen receptor modulator. J Bon Min Metab 1994;12:9-20.

3. Reddel LL, Sutherland RL. Tamoxifen stimulation of human breast cancer cell proliferation in vitro. A possible model for tamoxifen tumour fare. Eur J Cancer Clin Oncol 1984;11:1419-24.

4. Bonadonna G. Cancer of the breast. In: Bonadonna G, Robustelli Della Cuna G. Handbook of Medical Oncology. Milan: Masson; 1988. p. 407-32.

5. Bonadonna G, Bernardo G, Luca G, Robustelli Della Cuna G. Pharmacology, clinical toxicity, dosage and general indications of growth inhibiting compounds. Cancer of the breast. In: Bonadonna G, Robustelli Della Cuna J. Handbook of Medical Oncology. Milan: Masson; 1988. p. 335-77.

6. Iacobelli S, Lippman ME, Robustelli Della Cuna G. The role of tamoxifen in breast cancer. New York: Raven Press; 1982.

7. Sharma P, Kumar P, Sharma R, Dikshit DK. Selective estrogen receptor modulators; role of side chain in activity modulation. Asian J Pharm Clin Res 2014;7:272-4.

8. Binkhorst L, Mathijssen RH, Jager A, van Gelder T. Individualization of tamoxifen therapy: much more than just CYP2D6 genotyping. Cancer Treat Rev 2015;41:289-99.

9. Ahmad A, Ali SM, Ahmad MU, Sheikh S, Ahmad I. Orally administered endoxifen is a new therapeutic agent for breast cancer. Breast Cancer Res Treat 2010;122:579-84.

10. Howell A, De Friend D, Anderson E. Mechanisms of response and resistance to endocrine therapy for breast cancer and the development of new treatments. Endocr Relat Cancer 1993;43:5-21.

11. Westerberg H, Nordenskjould B, Schriver A, Notter G. Antioestrogen therapy of advanced mammary carcinoma. Acta Radiol Ther Phys Biol 1976;15:513-8.

12. Mouridsen H, Palshof T, Patterson J, Battersby I. Tamoxifen in advanced breast cancer. Cancer Treat Rev 1978;5:131-41.

13. Manni A, Baha'uddin MA. Tamoxifen-induced remission in breast cancer by escalating the dose to $40 \mathrm{mg}$ daily after progression on 20-20 mg daily: a case $\backslash$ report and review of the literature. Cancer 1981;48:875-8.

14. Hsu SM, Raine L, Fanger H. Self sandwich method. An improved immunoperoxidase technic for the detection of small amounts of antigens. Am J Clin Pathol 1980;4:32-74.

15. Meeting on the standardisation of reporting results of cancer treatment: In: WHO Handbook for Reporting Results of Cancer Treatment. World Health Organization. Geneva; 1979.

16. Farante G, Costa A, Arrighi A, Rancati A, Cuneo J, Borhi L, et al. Nueva estrategia frente al cancer de mama: la quimioprevención com tamoxifen. Tumor 1994;7:33-90.

17. Early Breast Cancer Trialists' Collaborative Group: Systemic treatment of early breast cancer by hormonal, cytotoxic or immune therapy. Lancet 1992;4:1-15.
18. Qureshi SS, Gupta JK, Shah K, Upmanyu N. Prevalence and risk factor of polycystic ovarian syndrome. Asian J Pharm Clin Res 2016;9:23-5.

19. Maurya H, Kumar T. A review on comprehensive overview in the management of nephrotic disorders. J Crit Rev 2016;3:34-43.

20. Peyrade F, Frenay M, Etienne MC, Ruch F, Guillemare C, Franóis $\mathrm{E}$, et al. Age-related difference in tamoxifen disposition. Clin Pharmacol Ther 1996;59:401-10.

21. Andrade JM, Marana HRC, Filho JMS, Murta EFC, Velludo MAL, Bighetti S. Indicadores clínicos com valor prognóstico no tratamento neo-adjuvante de carcinoma avançado de mama. Acta Oncol Bras 1994;14:180-6.

22. Jordan VC. Metabolites of tamoxifen in animals and man: identification, pharmacology, and significance. Brest Cancer Res Treat 1982;2:123-8.

23. Meriel P, Golder M, Elizabeth A, Phillips D, Fahmy R, Preece PE, et al. Plasma hormones in patients with advanced breast cancer treated with tamoxifen. Eur J Cancer 1976;12:719-23.

24. Lerner HJ, Band PR, Israel I, Leung BD. Phase II study of tamoxifen: report of 74 patients with stage IV breast cancer. Cancer Treat Reprod 1976;60:1431-5.

25. Stoll BA. Prognostic indices in breast cancer. In: Stoll BA. Pointers to Cancer Prognosis. Martinius Nijhoff: Dordrecht; 1987. p. 195.

26. Ward HWC. Anti oestrogen therapy for breast cancer: a trial of tamoxifen at two dose levels. Br Med J 1973;1:13-4.

27. Ward HWC, Arthur K, Banks AJ, Bond WH, Brown I, Freeman $\mathrm{WE}$, et al. Anti oestrogen therapy for breast cancer-a report on 300 patients treated with tamoxifen. Clin Oncol 1978;4:11-7.

28. Adam HK. Pharmacokinetic studies with nolvadex. Rev Endocr Relat Cancer 1981;9:131-43.

29. Wada T, Koyama H, Terasawa T, Hongo E. Tamoxifen: its pharmacokinetics in blood concentration in human blood and how it changes. Jpn Basic Pharmacol Ther 1980;8:49-56.

30. Patterson JS. Clinical aspects and development of antiestrogen therapy: a review of the endocrine effects of tamoxifen in animals and man. J Endocrinol 1981;89:67-75.

31. Ducharme J, Fried K, Shenouda G, Leyland-Jones B, Wainer IW. Tamoxifen metabolic patterns within a glioma patient population treated with high-dose tamoxifen. $\mathrm{Br} \mathrm{J}$ Clin Pharmacol 1997;43:189-93.

32. Walko CM, McLeod H. Use of CYP2D6 genotyping in practice: tamoxifen dose adjustment. Pharmacogenomics 2012;13: 691-7.

33. Ruddy KJ, Desantis SD, Gelman RS, Wu AH, Punglia RS, Mayer EL, et al. Personalized medicine in breast cancer: tamoxifen, endoxifen, and CYP2D6 in clinical practice. Breast Cancer Res Treat 2013;141:421-7.

34. Schiavon G, Smith IE. Endocrine therapy for advanced/ metastatic breast cancer. Hematol Oncol Clin North Am 2013;27:715-36.

35. Dickschen K, Eissing T, Murdter T, Schwab M, Willmann $\mathrm{S}$, Hempel G. Concomitant use of tamoxifen and endoxifen in postmenopausal early breast cancer: prediction of plasma levels by physiologically-based pharmacokinetic modeling. Springerplus 2014;3:285.

\section{How to cite this article}

- Bruno Jose Dumet Fernandes, Angelo Do Carmo Silva Matthes, Sergio Bighetti, Juliana Dumet Fernandes, Vera Lucia Lanchote, Catharina Rodrigues Pinto Lopes. Correlation between plasma tamoxifen concentration and tumor response in patients with breast cancer: at neoadjuvant treatment with tamoxifen. Int J Pharm Pharm Sci 2017;9(9):100-106. 